\title{
Thermo-Mechanical FE-Analysis of Residual Stresses and Stress Redistribution in Butt-Welding of a Copper Canister for Spent Nuclear Fuel
}

\author{
Lars-Erik Lindgren"), Hans-Åke Häggblad ${ }^{1)}$, Lennart Josefson²) and Lennart Karlsson ${ }^{1)}$ \\ 1) Luleå University of Technology, Sweden \\ 2) Chalmers University of Technology, Sweden
}

\begin{abstract}
The transient and residual temperature, stress and strain field present during electron beam welding of a plane copper end to a canister for spent nuclear fuel is calculated by use of FEM. The subsequent stress redistribution is calculated up to 10000 years. The canister consists of two concentric cylinders, an inner steel cylinder containing the spent nuclear fuel, and an outer copper cylinder. It was found that the maximum plastic strain (plastic + creep) accumulated in the (possibly brittle) heat affected zone is about $7 \%$ which seems to be well below the reported ductility for the copper used.
\end{abstract}

\section{INTRODUCTION}

In the Swedish nuclear waste program it has been decided that the spent nuclear fuel shall be placed in canisters in holes in tunnels located some $500 \mathrm{~m}$ underground in a rock storage. A layer of bentonite surrounds each canister in their respective holes. In the current canister design, the canister consists of two cylinders of roughly $5 \mathrm{~m}$ length, one inner cylinder made of steel and one outer cylinder made of copper. The outer diameter of the canister is $0.9 \mathrm{~m}$ and the wall thickness for each cylinder is $50 \mathrm{~mm}$. At the storage, the steel cylinder, which contains the spent nuclear fuel, is placed inside the copper cylinder. Thereafter, a copper end is butt welded to the copper cylinder using electron beam welding. Figure 1 shows the lay-out of the proposed canister including the copper end. With a new design of the copper end, an external ultrasonic inspection of the final butt weld, after the completion of the welding procedure, from both the inner and outer surface is made possible. At the present an experimental manufacturing facility has been built in Sweden, where the manufacturing and handling of the canisters will be investigated. The material surrounding the spent fuel rods in the steel cylinder is currently planned to be cast to a near exact shape. Although the specific manufacturing procedure for the copper canister is not decided upon, it is now clear that the composite copper-steel canister is the primary concept studied.

The primary objective in the mechanical design of the canister is to ensure no leakage of radioactive particles to the surroundings. This means, for example, that the risk for creep fracture must be assessed, and that the level of plastic strain in the canister due to the fabrication and to the design loading must be estimated and compared to values for the ductility of the copper material. During operation, the canister will be subject to an external pressure due to swelling of the bentonite. The interaction between the welding residual stresses and the stresses caused by the swelling then becomes important, as well as the 
relaxation of these stresses during the operation phase when the canisters are located in the repository. Due to neutron reactions in the spent fuel, the canister will have a relatively high temperature, about $100 \mathrm{C}$, for a very long time period.

In a previous paper [1], the temperature, strain and stress fields present during the final circumferential butt welding and after cooling after welding were calculated numerically assuming rotational symmetry. For small initial gaps between the inner and outer cylinders they will come in contact during the welding which results in a complex welding residual stress field. With no contact, the welding residual stress field in the copper cylinder will be similar to that in a butt-welded pipe. In [2] the cold forming (rolling) and subsequent longitudinal seam welding of two copper half cylinders (forming the outer copper cylinder) was studied.

In the present paper, the final circumferential butt welding studied again as in [1], however this time for the case with the new design of the copper end having a more complex shape. In addition to the calculations in [1], the subsequent stress redistribution under 10000 years when the canister is subject to an external (swelling) pressure of $15 \mathrm{MPa}$, see also [3]. The in-hose code SIMPLE [4] for coupled thermo-mechanical finite element analysis is used for the numerical simulations. Large strains are assumed and the contact conditions present in the canister when the sweeling pressure has forced the outer copper cylinder to come in contact with the inner steel cylinder which is accounted for in a simplified manner.

One may note that the design of the canister includes the assessment of the behaviour during some postulated failure modes, like shearing of the canister due to tectonic rock movements during a forthcoming ice age, buckling of the steel canister due to the external pressure, and growth of surface cracks. These failure modes are studied in other parts of the nuclear waste program.

\section{MODELLING}

The finite element mesh consists of 562 elements and 680 nodes. The time stepping has a minimum time step of $0.02 \mathrm{sec}$ during welding. The length of the time steps increases up to $70 \mathrm{hr}$ during the application of the external pressure and further increasing to 30 years at the end of the analysis. A graded quad element, see [5] which has piecewise linear interpolation functions is used in the model. The graded element alleviates the creation of a graded mesh. The analysis accounts for large deformations. A special Winkler foundation was included in the model to imitate the support of an inner steel cylinder which will come into contact with the copper canister during the application of the external pressure. An initial gap of $2 \mathrm{~mm}$ was set between the Winkler support and the copper canister. The stiffness of this support was taken from a separate analysis [6].

The thermal material data for the copper alloy were taken from handbooks. A thermalelastic-plastic model with linear isotropic hardening is used in the mechanical analysis of the welding. The creep effects are taken into account using a Norton type creep law with strain hardening, see [7] for a description of the model and used material data which is determined by using optimisation methods.

\section{CALCULATIONS}

The temperature, stress and strain fields present in the canister during the welding, the relaxation phase and during the applying of the deposition pressure are calculated numerically by use of the thermo-mechanically coupled finite element code SIMPLE [4]. The calculations are performed assuming rotational symmetry. One half of the canister is 
modelled. The welding starts at 4 seconds and is finished after 10 seconds. The creep relaxation starts after cooling to $200 \mathrm{C}$. This occur after 300 seconds (5 minutes). The deposition pressure is applied after 1 week, increases linearly to $15 \mathrm{MPa}$ after 2 years. The calculations are carried out until 10000 years.

\section{RESULTS}

In Figure 2 the temperature field is presented at four different times $5 \mathrm{~s}, 20 \mathrm{~s}, 300 \mathrm{~s}$ and 1 week. In Figure 3 the axial deflection of the centre of the copper end is shown as function of time (from the actual welding to 10000 years). In particular Figure 2 shows maximum outward deflection (after 20s), start of creep relaxation (after 300s), application of the external pressure (after one week) and when the copper canister gets in contact with the steel canister. Figure 4 shows the hoop stresses at four different times 20s, 300s, 1 week and after 10000 years. Figure 5 shows the radial stresses at two different times 1 week and after 10000 years. Figure 6 shows the axial stresses at two different times 1 week and after 10000 years. Figure 7 shows effective plastic strains at two different times 1 week and after 10000 years.

\section{DISCUSSIONS AND CONCLUSIONS}

Figure 2 shows clearly a number of different steps in finding the residual stresses due to welding, the start of creep relaxation, application of external pressure and the time when the steel cylinder and the copper cylinder get in contact with each other. It is noted in Figure 4 that large tensile hoop stresses appear already after $20 \mathrm{~s}$. After $300 \mathrm{~s}$ the maximum tensile hoop stress is lower than at 20 s. The cross-sectional area where the hoop stress is tensile is larger at $20 \mathrm{~s}$ than at $300 \mathrm{~s}$. The residual hoop stresses are tensile at large areas, which is noted at time 1 week. The hoop stresses become gradually compressive which is illustrated by the result after 10000 years.

The change of the effective plastic strain between the time 1 week and 10000 years is relatively small. The maximum plastic strain (plastic + creep) accumulated in the (possibly brittle) heat affected zone is about $7 \%$ which seems to be well below the reported [8] ductility for the copper used.

\section{ACKNOWLEDGEMENT}

The work was financial supported by the Swedish Nuclear Fuel and Waste Management Co (SKB). 


\section{REFERENCES}

1. Josefson, B.L., Karlsson, L., Lindgren, L.-E. and Jonsson, M., "Thermomechanical FEanalysis of butt-welding of $\mathrm{Cu}-\mathrm{Fe}$ canister for spent nuclear fuel", Transactions of the 12th International Conference on Structural Mechanics in Reactor Technology (SMiRT12), Elsevier Science Publishers, Amsterdam, The Netherlands, Vol. N, pp 315-320, 1993.

2. Josefson, B.L., Lindgren, L.-E., Häggblad, H.-Å. and Karlsson, L., "Thermomechanical FE-analysis of the fabrication of a $\mathrm{Cu}-\mathrm{Fe}$ canister for spent nuclear fuel", Transactions of the 13th International Conference on Structural Mechanics in Reactor Technology (SMiRT-13), Elsevier Science Publishers, Amsterdam, The Netherlands, Vol. I, pp 275$280,1995$.

3. Josefson, L., Karlsson, L., and Häggblad, H.-A., Stress redistribution and void growth in butt-welded canisters for spent nuclear fuel, SKB Technical Report 93-01, Swedish Nuclear Fuel and Waste Management Co, Stockholm, Sweden, 1993.

4. Lindgren, L.-E. User's manual for SIMPLE - Finite Element Program for Simulation of Material Processing, Division of Computer Aided Design, Luleå University of Technology, Luleå, Sweden, 1996.

5. McDill, J.M.J., Goldak, J.A., Oddy, A.S., and Bibby, M.J., 1soparametric quadrilaterals and hexahedrons for mesh grading algorithms, Comm. Appl. Numer. Methods, Vol 3, pp. 155-163. 1987.

6. Savås, L., Inkapsling, Behållare för utbränt kärnbränsle, Samverkan mellan stålcylinder och kopparhölje (in Swedish), SKB Projekt PM, 94-21.500-03, 1993.

7. Häggblad, H.-̊̊., Lindgren, L.-E., Karlsson, L. and Josefson, L., Constitutive models for copper with experimentally determined material parameters, Luleå University of Technology, Luleå, Sweden, 1996.

8. Henderson, P. J., Österberg, J.O. and Ivarsson, B., Low temperature creep of copper intended for nuclear waste containers, SKB Technical report 92-04, Swedish Nuclear Fuel and Waste Management Co, Stockholm, Sweden, 1992. 

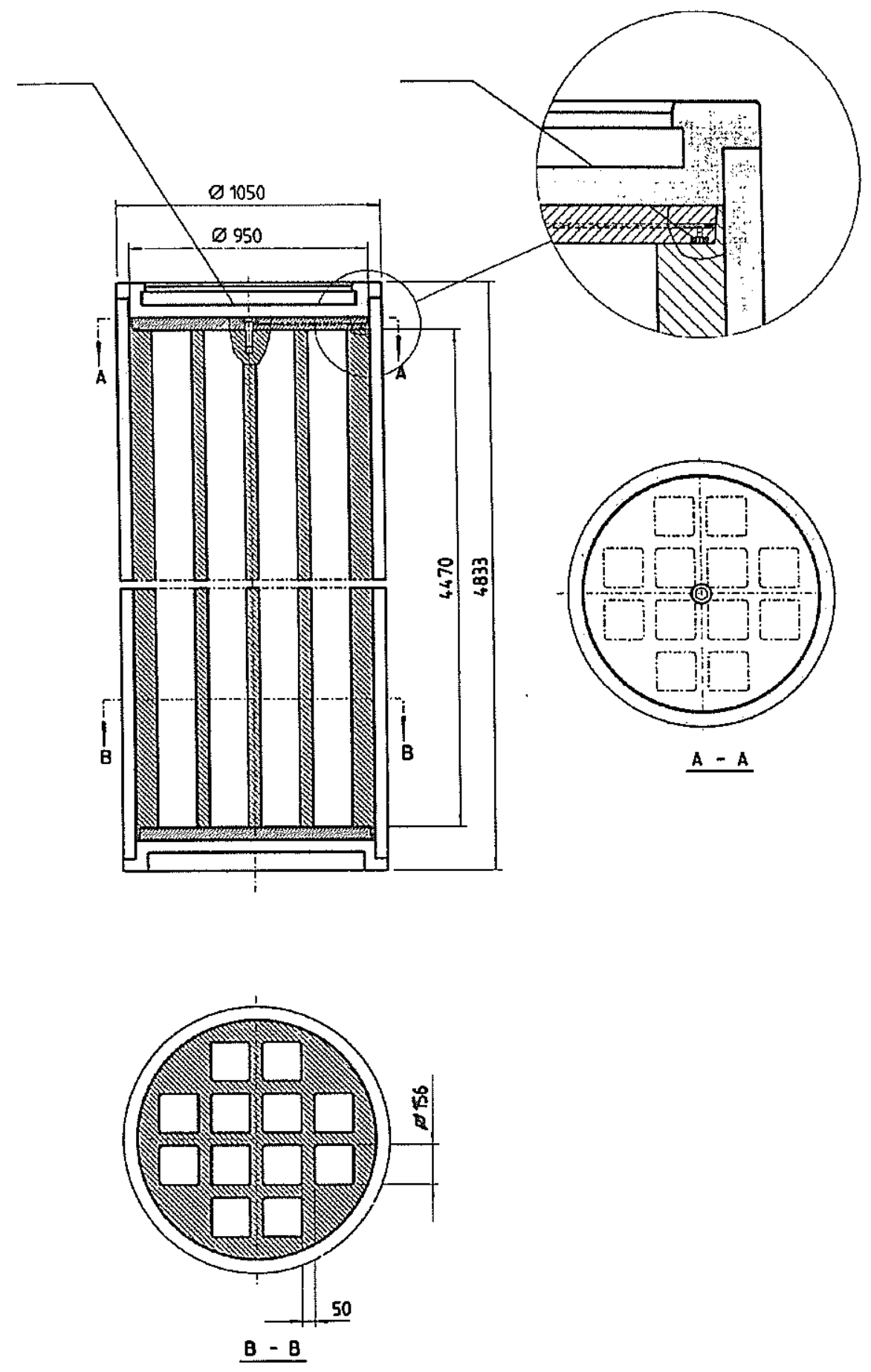

Figure 1. Geometry of canister. Dimensions in mm. 
Time $=5$ sec.

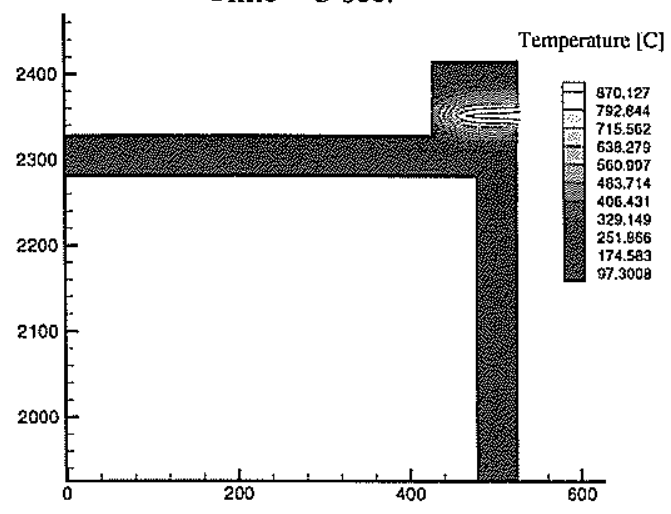

Time $=300 \mathrm{sec}$.

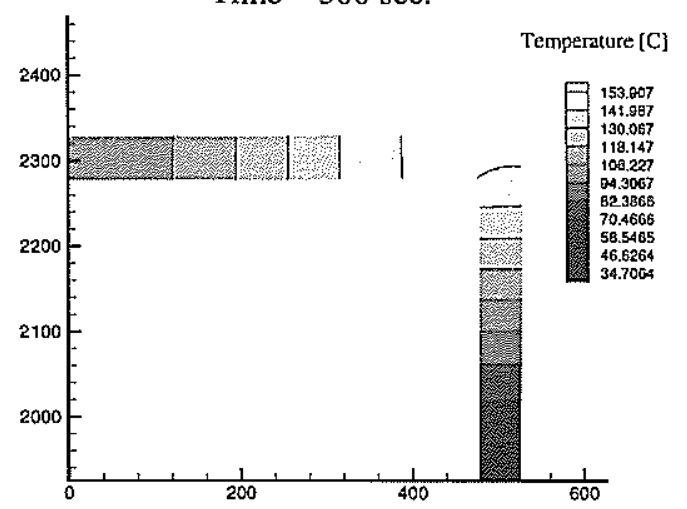

Time $=20 \mathrm{sec}$.

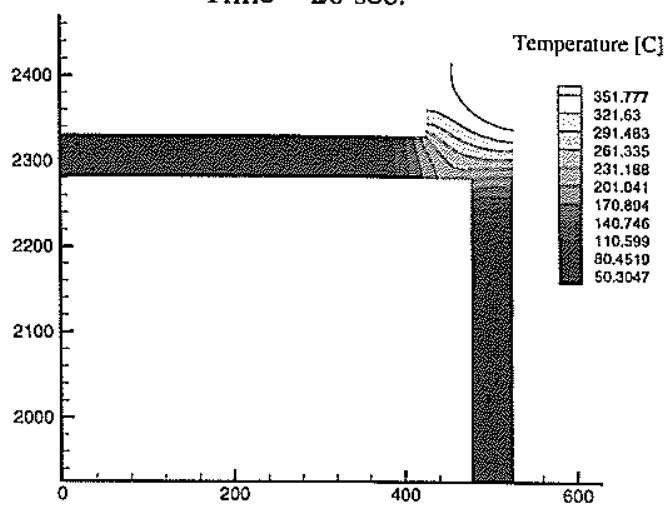

Time $=1$ week

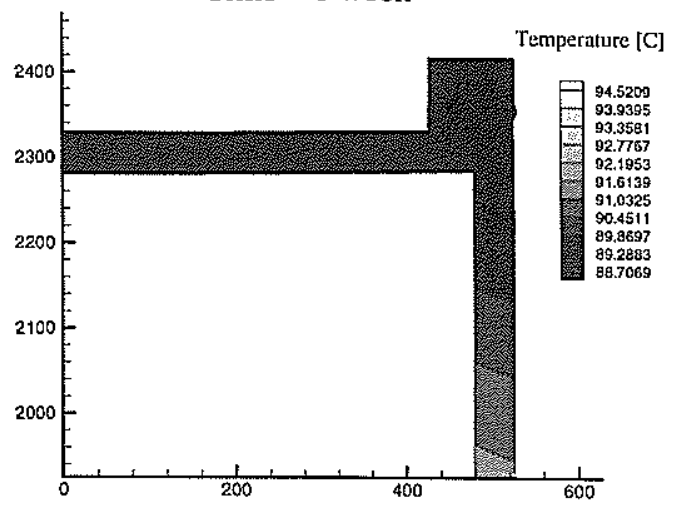

Figure 2. Temperature distribution

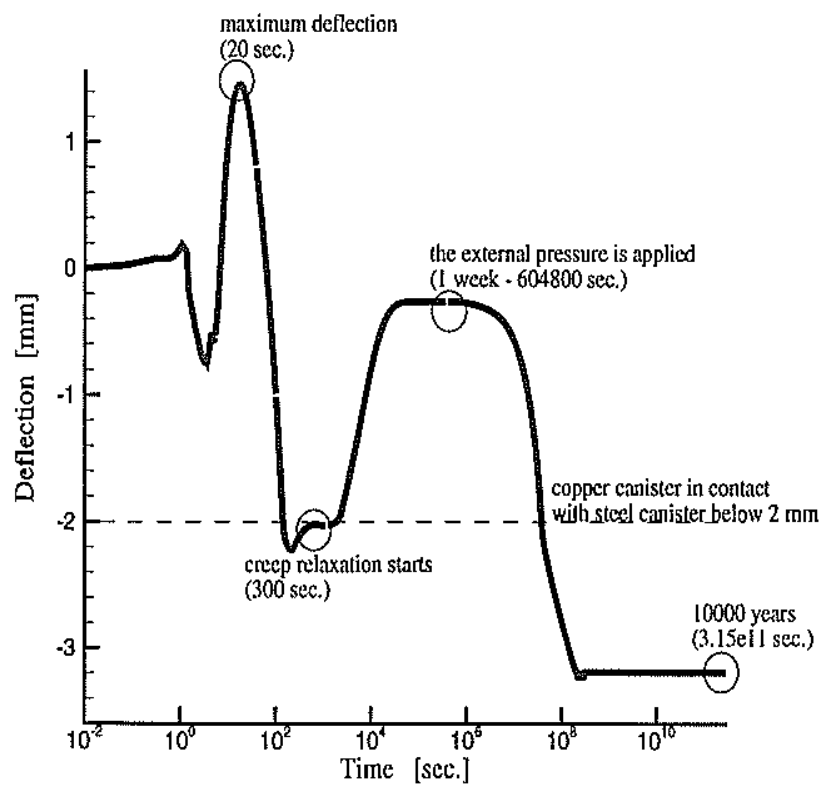

Figure 3. Axial deflection of the centre of the copper end. 
Time $=20 \mathrm{sec}$.

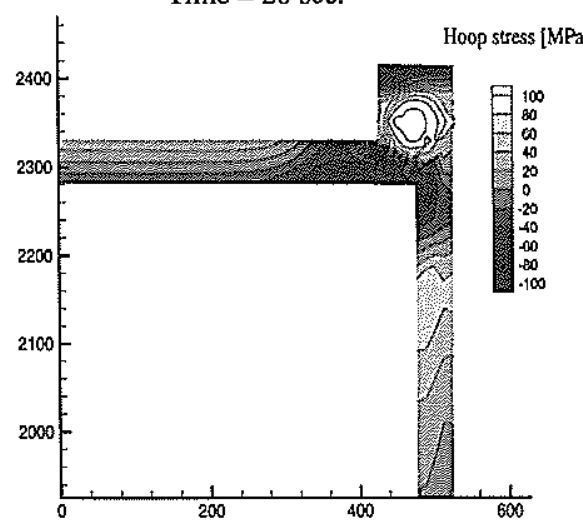

Time $=1$ week

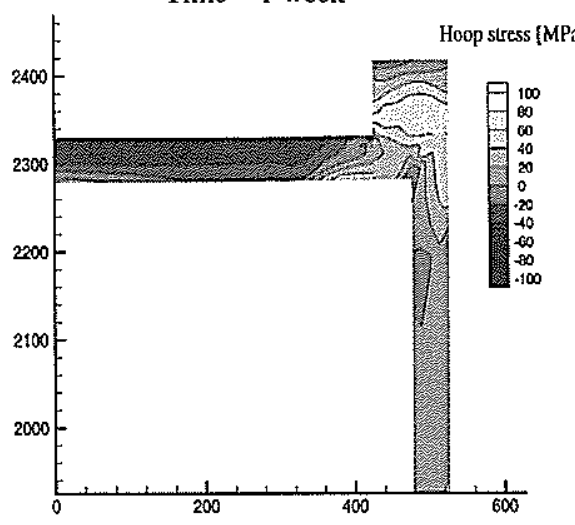

Figure 4. Hoop stresses

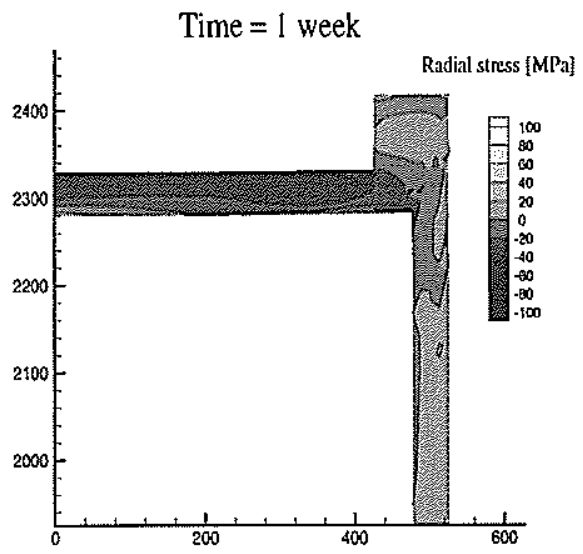

Time $=300 \mathrm{sec}$

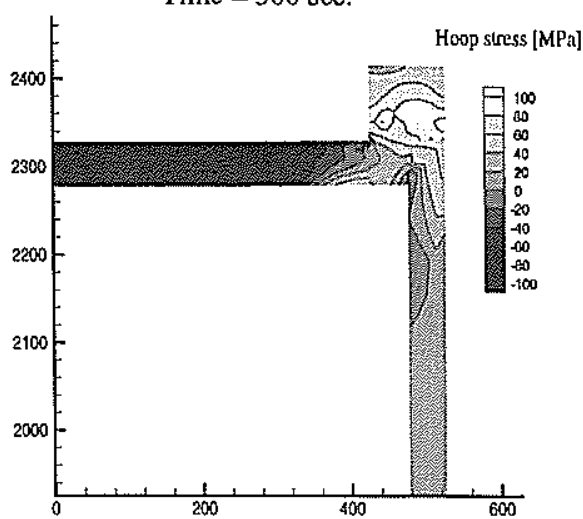

Time $=10000$ years

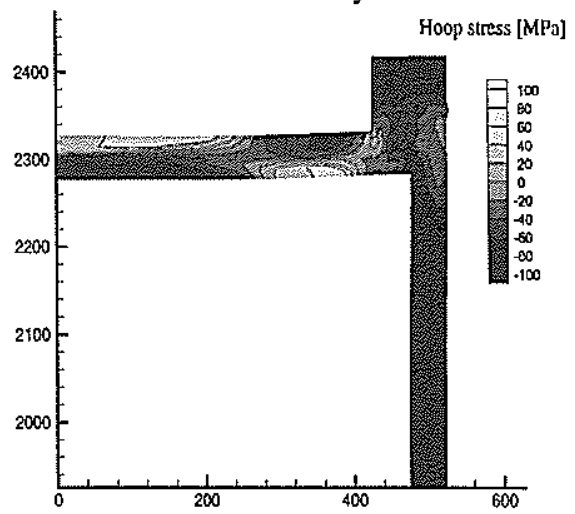

Time $=10000$ years

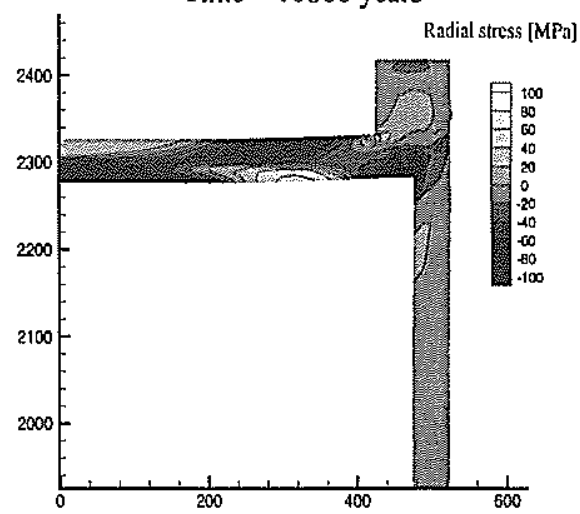

Figure 5. Radial stresses 

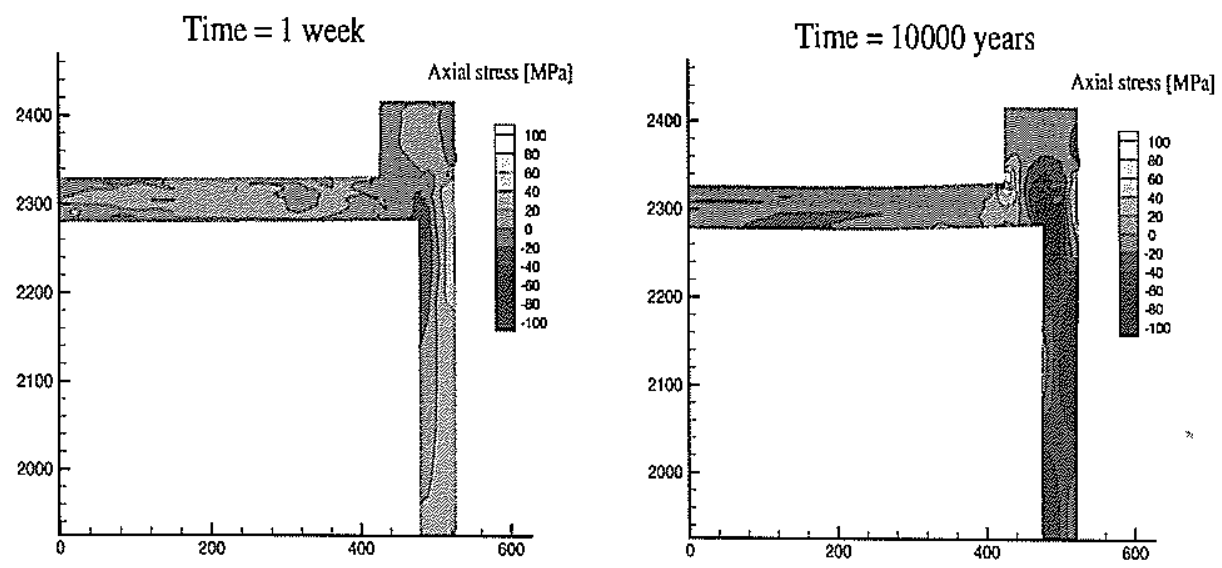

Figure 6. Axial stresses
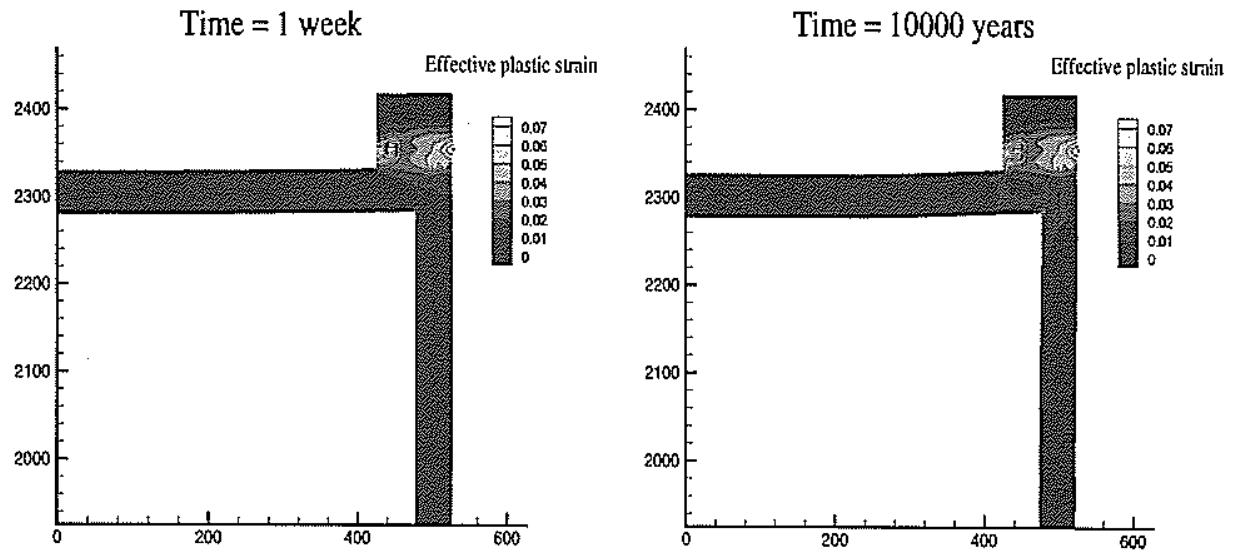

Figure 7. Effective plastic strains 